\section{Caracterização socioambiental do município de Caucaia (CE) utilizando sistema de informação geográfica (sig): subsídios para o ordenamento territorial}

\begin{abstract}
Resumo: 0 município de Caucaia, localizado no Estado do Ceará, vem apresentando nos últimos anos um grande crescimento populacional, desencadeando uma significativa expansão urbana. Nesse contexto, desenvolveu-se um Sistema de Informações Geográficas (SIG) com o objetivo principal de realizar a caracterização socioambiental e auxiliar as atividades vinculadas à gestão e ao ordenamento territorial. Na concepção do sistema, utilizaram-se ortofotocartas nas escalas 1:20.000 (área do município) e 1:2.000 (área da sede urbana), gerando-se uma proposta de agrupamento de dados cartográficos mapeados em nível de detalhe. A partir do SIG, podem-se realizar análises e consultas (espaciais ou tabulares), permitindo a visualização dos dados geográficos e otimizando a busca das informações, contribuindo de maneira direta na tomada correta de decisão por parte dos gestores públicos. Um ponto a ser destacado é o potencial do sistema para futuras atualizações, sendo o mesmo dinâmico.
\end{abstract}

\section{Environmental and social characteristics of the city of Caucaia (CE) using the geographic information system (Gis): subsidies for planning territory}

\footnotetext{
Abstract: The municipality of Caucaia, located in the State of Ceará, has shown in recent years a great population growth, leading to a significant urban expansion. In this context, it has developed a Geographic Information System (GIS) with the main objective of realizing the socio-environmental and auxiliary activities related to management and land use. In designing the system, we used orthophotos at scales 1:20,000 (area of the city) and 1:2,000 (urban area of the seat), generating a proposed grouping of cartographic data mapped at the level of detail. From the GIS, one can perform analyzes and queries (spatial or tabular), allowing the visualization of geographic data and optimizing the search of information, contributing in a direct way in making the correct decision on the part of public managers. A point to note is the potential for future system upgrades, and the same dynamic.
}

Cleyber Nascimento de Medeiros*

Marcos José Nogueira de Souza**

Daniel Dantas Moreira Gomes***

Emanuel Lindemberg Silva Albuquerque ${ }^{\star * * *}$

* Doutorando em Geografia pela Universidade Estadual do Ceará UECE

**Prof. Dr. da Pós-Graduação em Geografia da Universidade Estadual do Ceará - UECE

***Doutorando em Geologia pela Universidade Federal do Ceará UFC

Mestrando em Geografia pela Universidade Estadual do Ceará UECE

Palavras- chave: SIG Ordenamento Territorial;

Caucaia; Ceará

Key-Words: GIS; Land Management; Caucaia; Ceará. 


\section{Introdução}

Em virtude de ser a integralização e espacialização dos dados um valioso instrumento de gestão pública, tem-se constatado que 0 uso do geoprocessamento pode subsidiar o ordenamento territorial através de alternativas pertinentes e efetivas para os municípios. Dessa forma, o gestor público necessita conhecer geograficamente o seu território de atuação para uma administração eficiente, tendo em vista que os problemas a serem resolvidos possuem uma localização determinada.

Apesarde todas as discussões sobre crescimento econômico, meio ambiente, desenvolvimento e qualidade de vida, raramente se considera o princípio destes aspectos: o planejamento. Scarlato e Pontin (1999) definem o planejamento como sendo a soma de um conjunto de decisões baseadas em características técnicas do meio ambiente, nas necessidades da sociedade e nos fatores operacionais para uma dada região. Nesse sentido, decisões que considerem somente informações parciais podem desencadear um desequilíbrio, implicando em aumento de custos e diminuição de rendimentos, contribuindo também para os processos de degradação e de exaustão dos recursos naturais. Entende-se, portanto, que critérios subjetivos devem ser substituídos por análises mais abrangentes e consistentes que deem subsídios ao zoneamento territorial.

Para Santos (2004), a organização do espaço sempre foi uma das prioridades para as pessoas que se propõem a viver em grupos com objetivos e normas comuns. A manutenção da biodiversidade e a mitigação dos conflitos são importantes premissas para a definição dos procedimentos de planejamento, nos quais, o ordenamento territorial e a gestão ambiental são partes essenciais para um planejamento adequado.

Conforme Cunha (2001), para que as ações do poder público sejam orientadas às necessidades da comunidade e compatíveis com a realidade dos municípios, é importante conhecê-los segundo as suas potencialidades e vulnerabilidades ambientais, sociais e econômicas. Nesta perspectiva, 0 ordenamento territorial surge como um importante delineador das condições organizacionais e da funcionalidade dos sistemas urbanos e/ou rurais inerentes ao espaço geográfico.

Desse modo, faz-se necessária a utilização de novas metodologias que contemplem a paisagem em seus diferentes aspectos, norteando a implantação de ações em apoio ao gerenciamento dos recursos naturais e da urbanização através da análise espacial. Portanto, uma base de dados com informações georreferenciadas sobre um município permite 0 aperfeiçoamento da gestão deste espaço a partir de suas características socioeconômicas e ambientais.

A utilização de um Sistema de Informações Geográficas (SIG) permite que dados georreferenciados sobre um território possam ser consultados e analisados espacialmente, facilitando a sua compreensão e auxiliando no processo de tomada de decisão por parte do poder público e da sociedade.

De acordo com o Ministério das Cidades (Mcid), os municípios brasileiros, de maneira generalizada, possuem escassos conhecimentos práticos em planejamento, apresentando graves dificuldades em atender às políticas públicas inerentes às ações de gestão do território. Ainda segundo o MCid, cerca de $80 \%$ das atividades que são efetuadas a nível municipal dependem do fator localização, o que proporciona uma ampla reflexão sobre as aplicabilidades dos SIG's como

Geografia Ensino \& Pesquisa, v. 16, n.2 p. 162 - 182, maio/ago. 2012

Caracterização socioambiental do município de Caucaia (ce) utilizando sistema de informação geográfica (sig): subsídios para o ordenamento territorial subsídio ao ordenamento territorial (BRASIL, 2010).

Nesse sentido, o gestor público depende do conhecimento geográfico de seu município para uma administração eficiente, afinal, as ações de gestão acontecem em lugares específicos, os problemas a serem resolvidos possuem uma determinada localização e o conhecimento do território possibilita um maior número de acertos na tomada de decisão (MEDEIROS, 2004).

Dentro desse contexto tem-se o município de Caucaia, o qual vem apresentando um elevado crescimento demográfico, bem como a execução de grandes projetos econômicos estão sendo implementados no território municipal e no seu entorno, citando, por exemplo, o Complexo 
Industrial e Portuário do Pecém (CIPP), o qual conterá uma refinaria, uma siderúrgica e uma zona de processamento de exportação (ZPE).

Tais projetos podem provocar impactos sobre os geossistemas, justificando a real necessidade da elaboração de um banco de dados georreferenciado e de um SIG que possua informações ambientais e socioeconômicas, servindo de ferramenta para auxiliar o planejamento municipal.

Assim, face à toda a complexidade existente na relação sociedade e natureza, o principal objetivo desse trabalho foi conceber um SIG para o município visando subsidiar as atividades relacionadas à gestão territorial e possibilitando a organização do espaço geográfico, tendo como escopo a caracterização socioambiental de Caucaia.

\section{Aspectos metodológicos}

Em virtude dos avanços tecnológicos experimentados nas mais diversas áreas do conhecimento, foi possível verificar uma evolução na área de SIG nos últimos anos, fruto das inovações que ocorreram em disciplinas distintas e pela troca e acréscimo mútuo do conhecimento interdisciplinar, proporcionando um diferencial na atualidade (SILVA, 1999). Dessa forma, muitos trabalhos abordam aplicações de SIG em estudos urbanos e de planejamento territorial, citando, por exemplo, Clarke (2002), Bolstad (2002), Medeiros et. al. (2005), Mitchell (2005), Albuquerque (2011), Gianuca e Tagliani (2012).

Nesse contexto, o SIG de Caucaia foi elaborado utilizando as ortofotocartas na escala 1:2.000 da sede municipal de Caucaia e das localidades de Jurema, Catuana, Mirambé, Icaraí, Iparana, Tabuba e Cumbuco (Figura 1), assim como as ortofotocartas na escala 1:20.000 de todo o território municipal, bem como de informações fornecidas pela Prefeitura Municipal de Caucaia, Instituto de Pesquisa e Estratégia Econômica do Ceará (IPECE) e Secretaria Estadual do Turismo (SETUR), almejando ter-se o máximo de dados em nível de detalhe sobre o território municipal.

O SIG de Caucaia foi concebido no âmbito do projeto da Base Cartográfica dos Municípios do Pólo Ceará Costa do Sol, projeto este elaborado através de um convênio celebrado entre 0 IPECE, Ministério do Turismo (MTur) e SETUR.

A Base Cartográfica dos Municípios do Pólo Ceará Costa do Sol foi gerada através de um levantamento aerofotogramétrico, elaborando ortofotocartas na escala de 1:20.000 para a área total dos municípios e na escala de 1:2.000 para as sedes municipais e distritos com vocação turística.

A aerofotogrametria digital tem sido largamente empregada em mapeamentos de áreas para diversas finalidades, servindo de insumo para a elaboração de estudos e projetos no intuito de ter-se um maior conhecimento do espaço geográfico através da análise das ortofotocartas (IPECE, 2008).

Ressalta-se que a precisão geométrica planimétrica e altimétrica alcançada pelas ortofotocartas nas duas escalas de mapeamento atendeu ao Padrão de Exatidão Cartográfica (PEC) na classe A, estabelecido pelo Decreto Federal $n^{0} .89 .817$ de 20 de Junho de 1984, tendo um erro-padrão de 5,58 metros na planimetria e 1,59 metros na altimetria para a escala 1:20.000, enquanto que para o mapeamento na escala 1:2.000 teve-se um erro-padrão de 0,45 metros na planimetria e 0,28 metros na altimetria.

Foram mapeados cerca de 100 temas, sendo os mesmos gerados a partir da interpretação das ortofotos, onde também foi realizado o trabalho de reambulação em campo visando à coleta de toponímia, ou seja, o nome dos rios, lagoas, hotéis, restaurantes, escolas, hospitais, entre outros.
Geografia Ensino \& Pesquisa, v. 16, n.2 p. 162 - 182, maio/ago. 2012

Medeiros, C. N.; Souza, M. J. N; Gomes, D. D. M.; Albuquerque, E. L. S. 


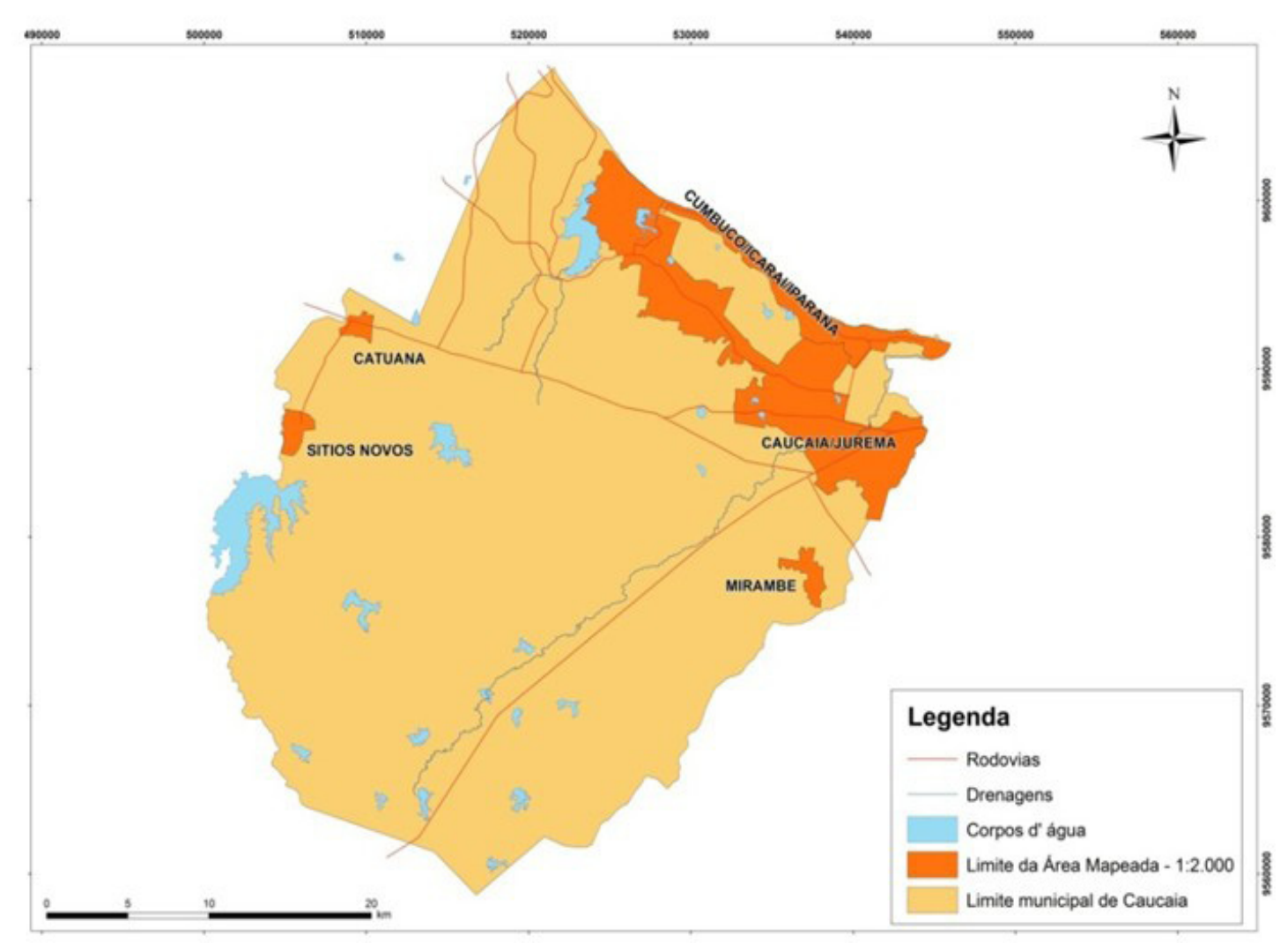

Figura 1- Áreas mapeadas (cor laranja) na escala 1:2.000.

Fonte: Elaboração própria.

Para que fossem posteriormente vinculadas às informações do banco de dados da Secretaria de Finanças de Caucaia ao material cartográfico produzido, foi necessária a coleta em campo do "número de porta" de todos os lotes mapeados no município, permitindo a geocodificação e a criação de um cadastro georreferenciado no âmbito do uso da terra e do turismo.

A partir dessa geocodificação, pode-se planejar e melhorar, por exemplo, a arrecadação do Imposto Predial e Territorial Urbano (IPTU), possibilitando ao município investir em áreas de infraestrutura urbana, almejando melhorar a qualidade de vida da população local.

Elaboraram-se também os metadados para os temas inseridos no SIG, criando uma catalogação para os mesmos, apresentando informações sobre a descrição dos temas, parâmetros cartográficos e dos atributos.

Conforme CONCAR (2010), entende-se por metadados o conjunto de informações descritivas sobre os dados, incluindo as características do seu levantamento, produção, qualidade e estrutura de armazenamento, essenciais para promover a sua documentação, integração e disponibilização.

Visando uma melhor organização dos temas mapeados nas ortofotocartas, adaptou-se a

Geografia Ensino \& Pesquisa, v. 16, n.2 p. 162 - 182, maio/ago. 2012

Caracterização socioambiental do município de Caucaia (ce) utilizando sistema de informação geográfica (sig): subsídios para o ordenamento territorial categorização proposta pela CONCAR (2010) que abrange informações cartográficas mapeadas até a escala 1:25.000, criando assim uma estrutura de grupos de temas para dados cartográficos mapeados em nível de detalhe (1:2.000), conforme descrito a seguir:

- ORTOFOTOCARTAS - Neste grupo constam os limites das ortofotos da área agregada com as informações sobre a articulação das folhas na escala 1:2.000 e 1:20.000.

- ALTIMETRIA E APOIO DE CAMPO - Foram mapeados neste grupo: Pontos Cotados, Curvas de Nível Mestras e Intermediárias, Apoio Fotogramétrico, Vértice de Apoio Básico, Modelo Digital do Terreno, Mapa de Declividade. 
- INFRAESTRUTURA - Neste grupo encontram-se os temas: Poste de Transmissão, Luminárias, Torre de Energia Eólica, Poço, Reservatório, Tanque, Torre de Telecomunicação, Caixa d'Água, Torre de Transmissão, Linha de Transmissão e Encanamento/Adutora.

- TURISMO - Neste grupo foram mapeados: Restaurantes, Hotéis, Pousadas, Quiosques, Barracas e Atrativos turísticos.

- EQUIPAMENTOS PÚBLICOS, PRIVADOS E INSTITUCIONAIS - Foram mapeados neste grupo os temas: Posto de Combustível, Campo de Futebol, Delegacia, Posto da Cagece, Posto da Coelce, Correios, Cartório, Escolas (Municipais, Estaduais e Particulares), Cemitério, Câmara Legislativa, Posto de Saúde, Clube, Praça, Hospital, Quadra de Esporte, Igreja, Comércio, Prefeitura, Associação, Indústria, Banco, Posto da Telemar, Creche, Instituição Pública e Equipamentos de Uso Comum.

- USO DA TERRA - Neste grupo têm-se os seguintes temas: Divisa de Propriedade, Muro, Alambrado, Muro de Arrimo, Cerca, Construção, Cobertura, Piscina, Ruína e Lote.

- HIDROGRAFIA - Neste grupo foram mapeados: Linha do Oceano, Rio Intermitente, Rio Perene, Barragem, Sangradouro, Canal, Vala/Dreno, Canaleta, Lago/Lagoa Perene, Lago/Lagoa Intermitente e Açude.

- SISTEMA VIÁRIO - Foram mapeados neste grupo os temas: Ponto de Ônibus, Via não Pavimentada, Via Pavimentada, Rodovia, Acostamento, Bueiro, Calçada, Caminho/Trilha, Escadaria/Rampa, Ferrovia, Ponte e Viaduto.

-ASPECTOS NATURAIS - Neste grupo encontram-se os seguintes temas: Taludes, Alagados, Brejos, Dunas, Erosão, Manguezais e Movimento de Terra.

- UNIDADES DE CONSERVAÇÃO E TERRAS INDÍGENAS - Foram mapeados neste grupo os temas: Parque Botânico do Ceará, APA do Estuário do Rio Ceará, APA do Lagamar do Cauípe e Terras Indígenas dos Tapebas.

- LIMITES POLÍTICOS - Neste grupo encontram-se os temas: Limite da Área Mapeada, Limites de Distritais, Limites de Bairros, Setores Censitários, Limite do Município de Caucaia.

Os temas gerados na base cartográfica do Pólo Ceará Costa do Sol estavam todos inicialmente no formato dwg, formato padrão do software Auto Cad Map®. Um projeto no Auto Cad Map $®$ é formado pela união de vários temas atuando em conjunto e para que esses temas fossem utilizados no SIG foi necessário isolar cada um deles deixando-os separados, fazendo-se imprescindível converter assim o formato dos arquivos de dwg para shapefile (shp), formato nativo do software Arcgis $9.3 \circledast$.

Os arquivos de geometria pontual ou linear foram inseridos diretamente no software ArcGis $9.3 \circledR$, pois o mesmo abre o formato dwg e transforma-o para o formato shp, mantendo com ele propriedades topológicas como: valor das curvas de nível em entidades do tipo linear bem como 0 valor da cota de aparelhos em entidades do tipo pontual. Para os arquivos de geometria poligonal foi criada uma topologia antes de os mesmos serem exportados para o ArcGis $9.3 \AA$. 0 propósito da criação da topologia é porque ela agrega informações aos polígonos, como por exemplo, a área e o perímetro do polígono. Por fim, cita-se que foi adquirida uma licença do software Arcgis 9.3®, visando o pleno uso do sistema.

\section{Caracterização socioambiental de Caucaia}

A área de estudo compreende o município de Caucaia (Figura 2), que integra a Região Metropolitana de Fortaleza (RMF), com cerca de 1.227,9 Km2 (IBGE, 2002), equivalente a 0,83\% da superfície estadual, com um contingente populacional de 325.441 habitantes e densidade demográfica de 265,04 hab./km2 (IBGE, 2010).

Geografia Ensino \& Pesquisa, v. 16, n.2 p. 162 - 182, maio/ago. 2012

Medeiros, C. N.; Souza, M. J. N; Gomes, D. D. M.; Albuquerque, E. L. S. 
O município limita-se ao Norte com o Oceano Atlântico e com São Gonçalo do Amarante, a Sul com Pentecoste e Maranguape, a Oeste com São Gonçalo do Amarante, Pentecoste e Maranguape e a Leste com Maranguape, Maracanaú e o município de Fortaleza (IPECE, 2010).

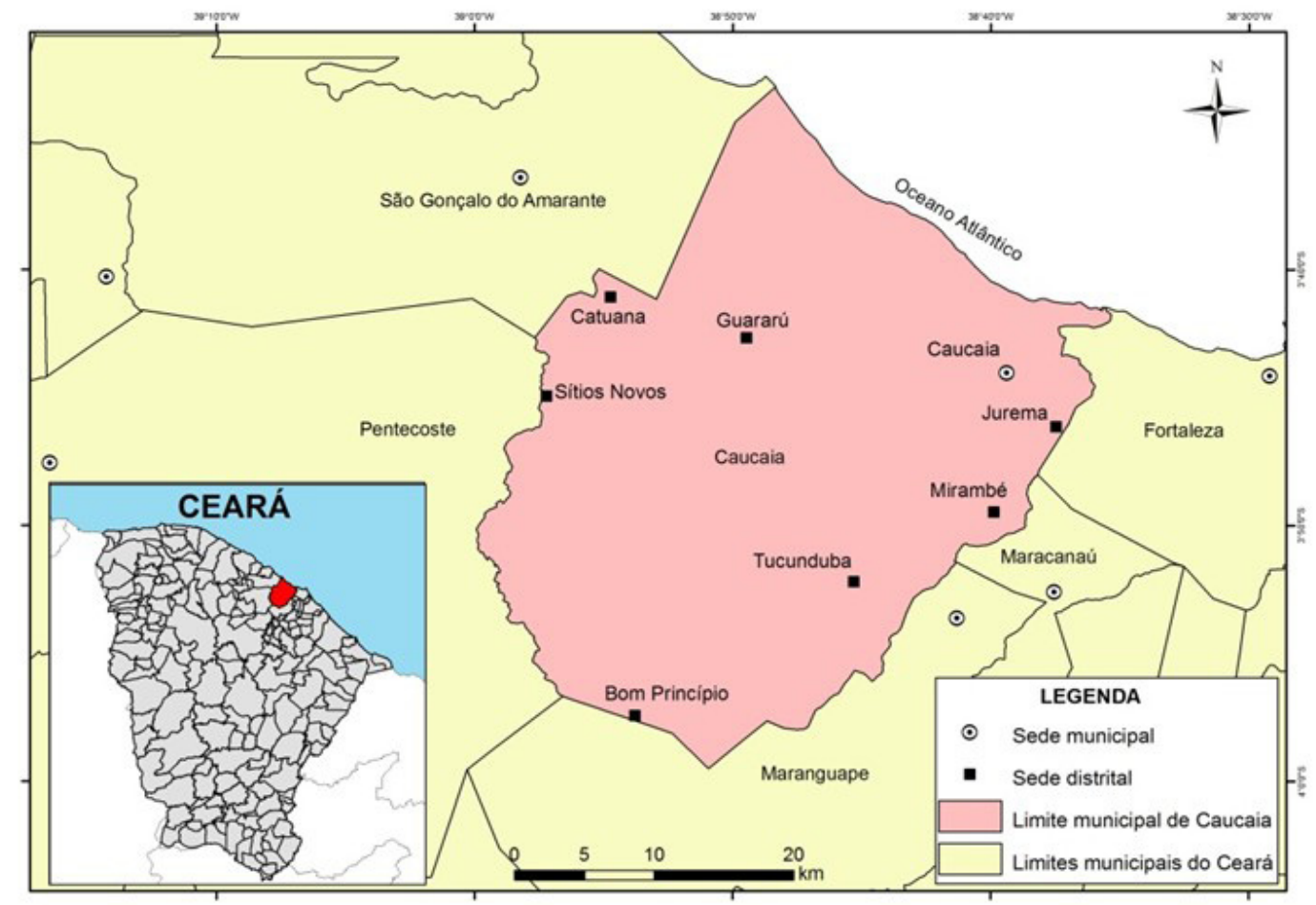

Figura 2- Localização da Área de Estudo. Fonte: Elaboração própria.

O acesso ao município de Caucaia é feito principalmente pelas rodovias BR-020 e CE-085, além de estradas secundárias. Caucaia está distante $16 \mathrm{Km}$ rodoviários de Fortaleza, estando as duas cidades interligadas através da ponte José Martins Rodrigues sobre o rio Ceará, que liga a Avenida Leste-Oeste à rodovia estadual CE-225, interligada com a BR-222 (MORAIS, 2010).

Em relação aos aspectos ambientais, a estrutura geológica do município foi estudada por Souza (1988), Souza et. al. (1995), sendo que a mesma apresenta dois conjuntos bem distintos: Coberturas sedimentares de idade Tércio-Quartenária e litologias do embasamento cristalino pré-cambriano.

Nesse contexto, geologicamente, o município de Caucaia pode ser caracterizado pela ocorrência de coberturas sedimentares cenozóicas sobrepostas a terrenos cristalinos précambrianos. As coberturas sedimentares são representadas pela formação Barreiras, coberturas coluviais-eluviais, depósitos eólicos (paleodunas e dunas móveis), depósitos flúvio-aluvionares e depósitos flúvio-marinhos (SOUZA, 2000).

Em termos de relevo, Caucaia é marcado por altitudes médias a baixas geralmente inferiores

Geografia Ensino \& Pesquisa, v. 16, n.2 p. 162 - 182, maio/ago. 2012

Caracterização socioambiental do município de Caucaia (ce) utilizando sistema de informação geográfica (sig): subsídios para o ordenamento territorial a 1.000 metros. 0 município é caracterizado pelos tabuleiros pré-litorâneos, depressão sertaneja englobando serras e campos de inselbergs, planícies fluviais, planícies flúvio-marinhas e campos de dunas, móveis ou fixas (SOUZA, op. cit.).

A Figura 3 apresenta o Modelo Digital do Terreno (MDT) de Caucaia, gerado a partir da interpolação de curvas de nível com equidistância de 5 metros usando o método TIN (Triangular Irregular Network), a partir de dados contidos no SIG. 


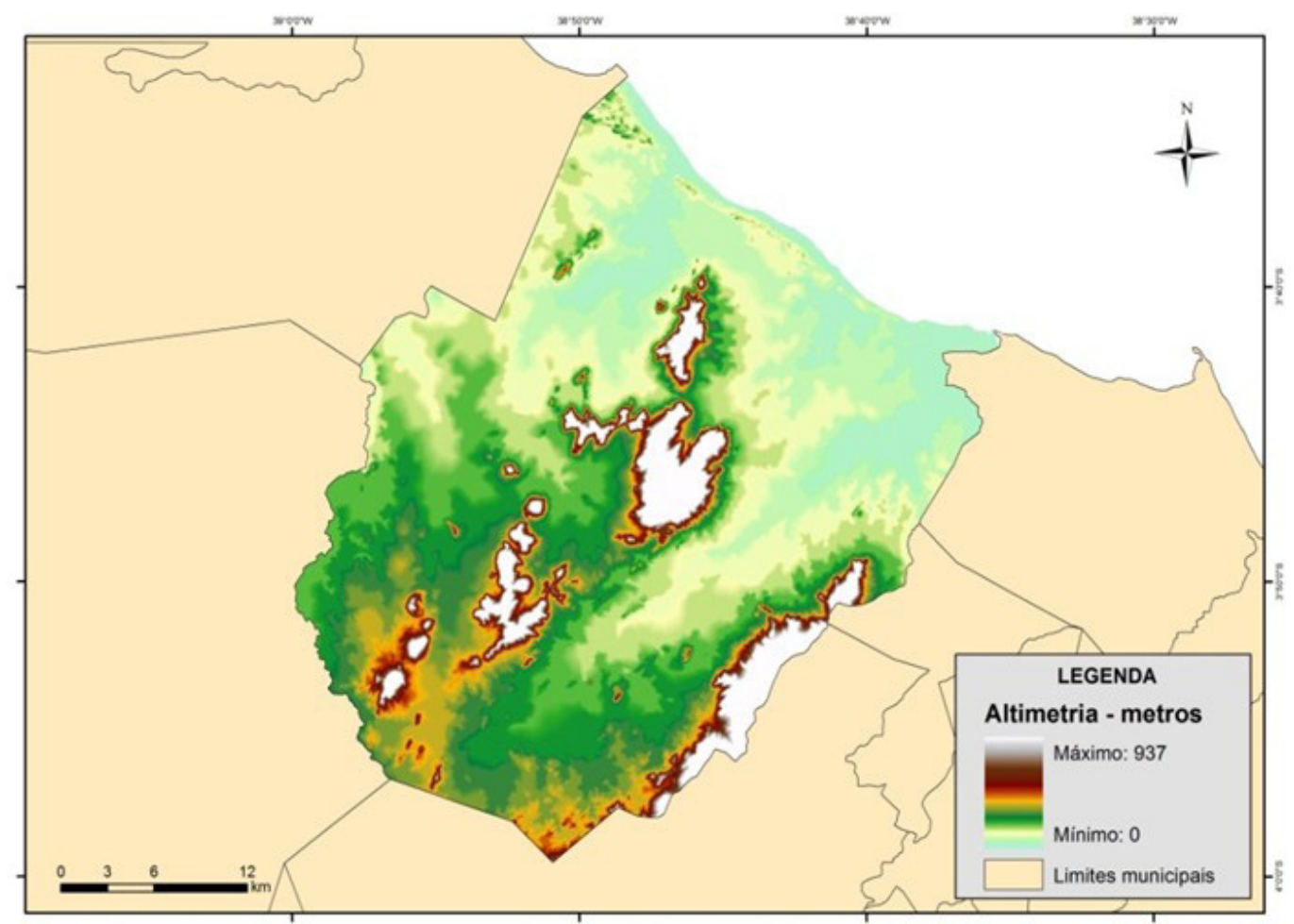

Figura 3- Modelo Digital do Terreno de Caucaia.

Fonte: Elaboração própria.

O clima na área de estudo é o tropical quente semiárido brando, ocorrendo também os climas tropical quente sub-úmido e tropical quente úmido. O período chuvoso é identificado entre os meses de Janeiro a Maio, com uma temperatura média anual variando de $26^{\circ} \mathrm{C}$ a $28^{\circ} \mathrm{C}$, possuindo uma precipitação pluviométrica média anual de 1.243,2 mm (IPECE, 2010).

Caucaia situa-se na bacia hidrográfica metropolitana e seus rios de maior porte são o Ceará, Cauipe e Anil. Encontram-se no contexto da bacia hidrográfica do município lagoas e açudes, com destaque para os açudes Sítios Novos e Cauipe (Figura 4). 


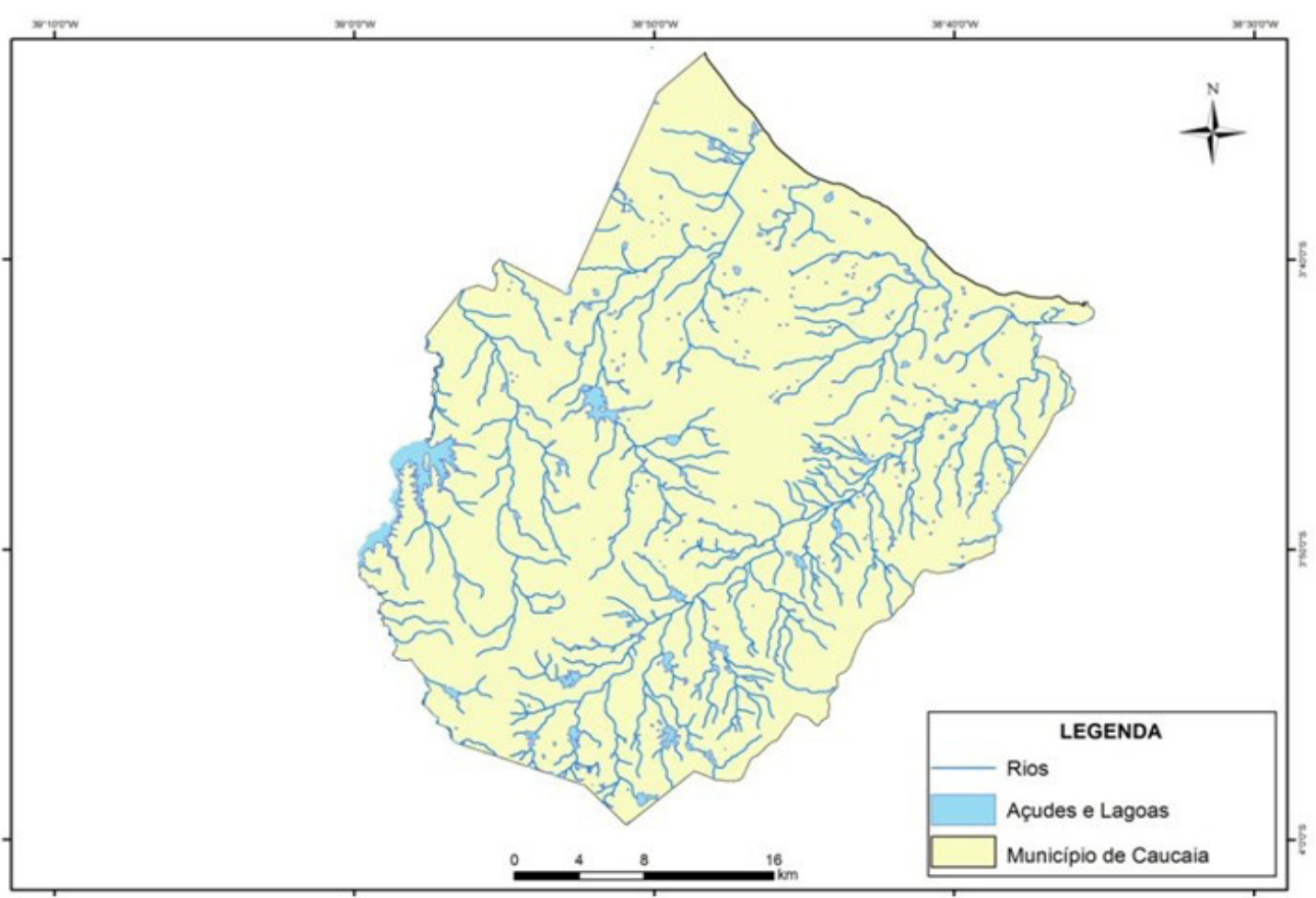

Figura 4- Mapa Hidrográfico de Caucaia, gerado a partir de dados contidos no SIG.

Fonte: Elaboração própria.

Quanto aos aspectos socioeconômicos, a população de Caucaia correspondia a 325.441 habitantes em 2010, sendo a segunda maior cidade cearense em termos de contingente populacional, atrás apenas da capital, Fortaleza (2.452.185 hab.). O município alcançou um crescimento relativo de $29,93 \%$ na última década, onde registrava 250.479 habitantes no ano 2000 , segundo dados dos censos demográficos do IBGE.

A Tabela 1 exibe a distribuição populacional de Caucaia em 2010 segundo os seus oito distritos. Verifica-se que $50,84 \%$ da população vivem no distrito sede, sendo os distritos de Jurema $(39,72 \%)$ e Catuana $(2,79 \%)$, os outros com maiores contingentes populacionais.

Tabela 1- População Total, Urbana e Rural, Caucaia e Distritos - 2010

Geografia Ensino \& Pesquisa, v. 16, n.2 p. 162 - 182, maio/ago. 2012

Caracterização socioambiental do município de Caucaia (ce) utilizando sistema de informação geográfica (sig): subsídios para o ordenamento territorial

\begin{tabular}{|c|c|c|c|c|c|c|}
\hline \multirow{2}{*}{ Distritos } & \multicolumn{2}{|c|}{ Total } & \multicolumn{2}{c|}{ Urbana } & \multicolumn{2}{c|}{ Rural } \\
\cline { 2 - 7 } & $\mathbf{N} .^{\circ}$ & $\begin{array}{c}\text { \% } \\
\text { (coluna) }\end{array}$ & $\mathbf{N .} .^{\circ}$ & \% (linha) & N. ${ }^{\circ}$ & \% (linha) \\
\hline $\begin{array}{c}\text { Município de } \\
\text { Caucaia }\end{array}$ & 325.441 & 100,00 & 290.220 & 89,18 & 35.221 & 10,82 \\
\hline Bom Principio & 3.257 & 1,00 & 1.196 & 36,72 & 2.061 & 63,28 \\
\hline Catuana & 9.092 & 2,79 & 1.878 & 20,66 & 7.214 & 79,34 \\
\hline Caucaia & 165.459 & 50,84 & 149.896 & 90,59 & 15.563 & 9,41 \\
\hline Guararu & 4.278 & 1,31 & 918 & 21,46 & 3.360 & 78,54 \\
\hline Jurema & 129.276 & 39,72 & 129.276 & 100,00 & - & - \\
\hline Mirambé & 5.076 & 1,56 & 2.609 & 51,40 & 2.467 & 48,60 \\
\hline Sítios Novos & 5.990 & 1,84 & 4.270 & 71,29 & 1.720 & 28,71 \\
\hline Tucunduba & 3.013 & 0,93 & 177 & 5,87 & 2.836 & 94,13 \\
\hline
\end{tabular}

Fonte: Censo Demográfico do IBGE, 2010. 
Dessa forma, verifica-se que o contingente populacional de Caucaia tem crescido com maiores taxas nas áreas urbanas, existindo a necessidade de aprofundar as discussões e reflexões no estudo do espaço urbano, servindo de orientação e subsídio para os investimentos na área de infraestrutura e nos diversos setores que compõem a gestão municipal. A Figura 5 apresenta a distribuição geográfica da população de Caucaia de acordo com os seus limites distritais, constatando-se um maior adensamento nos distritos localizados próximos a sede municipal.

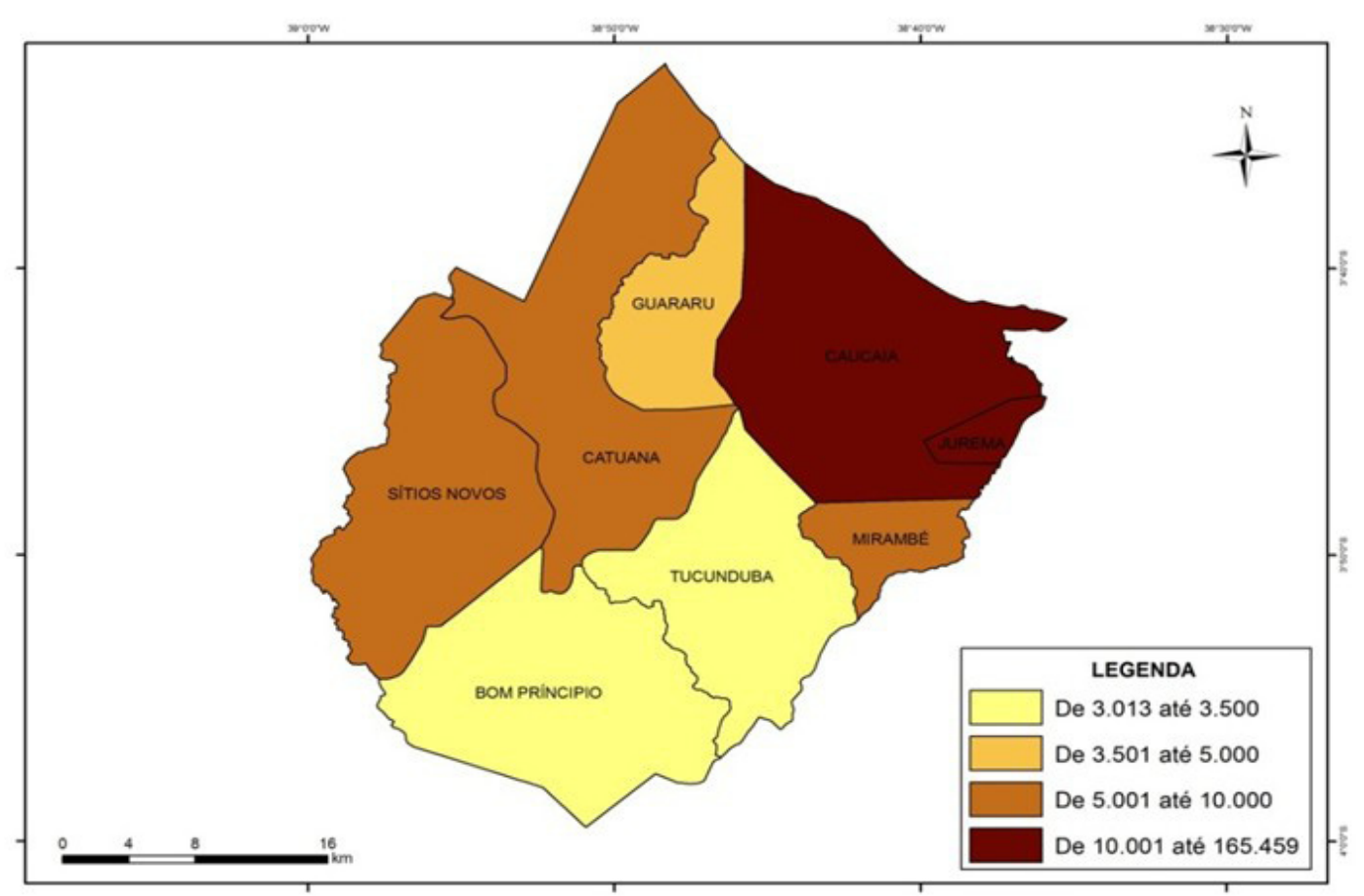

Figura 5- Mapa com a Distribuição populacional de Caucaia segundo distritos para o ano de 2010, gerado a partir de dados contidos no SIG.

Fonte: Elaboração própria.

A população do município tem uma distribuição equivalente segundo gênero, com uma proporção de $49,04 \%$ de homens e $50,96 \%$ de mulheres. Cerca de $27,28 \%$ da população tem menos de 14 anos de idade, 70,48\% possuí entre 15 e 64 anos e 2,24\% tem mais de 64 anos de idade, de acordo com dados do IBGE (2010). O grau de urbanização de Caucaia é de aproximadamente $89,18 \%$, correspondendo a um total de 290.220 moradores residindo em áreas urbanas do município. A taxa de analfabetismo da população com 15 anos ou mais de idade situou-se num patamar de $12,89 \%$ no ano 2010 , resultado melhor do que o verificado para o Estado (18,8\%). A renda per capita média da população de Caucaia registrou o valor de $\mathrm{R} \$ 405,51$ em 2010, sendo a $8^{a}$ maior do Ceará.

Um total de $82,48 \%$ dos domicílios são atendidos pelo serviço de coleta de lixo, sendo de $81,64 \%$ o percentual de domicílios ligados à rede geral de abastecimento de água. Já a proporção de domicílios com existência de energia elétrica alcançou a marca de 99,41\%, caminhando assim para a universalização deste serviço. Em contra partida, apenas $39,35 \%$ dos domicílios estão ligados à rede geral de esgoto. Assim, conclui-se que a taxa de cobertura de esgotamento sanitário ainda é baixa, necessitando de mais políticas de expansão da rede de coleta de esgotos no município no intuito de aumentar o percentual de cobertura, trazendo desta forma benefícios para a população em diversas áreas, como, por exemplo, na saúde e no meio ambiente.

Ressalta-se que todas as informações ambientais e socioeconômicas do município de Caucaia mencionadas nesta seção estão presentes no SIG elaborado, podendo-se efetuar consultas
Geografia Ensino \& Pesquisa, v. 16, n.2 p. 162 - 182, maio/ago. 2012

Medeiros, C. N.; Souza, M. J. N; Gomes, D. D. M.; Albuquerque, E. L. S. 
e análises integradas, consentindo-se assim realizarem-se atividades de planejamento visando à gestão e ao ordenamento territorial do município a partir de suas características socioambientais.

\section{Aplicações do SIG no ordenamento territorial}

A importância do uso de SIG na gestão pública se justifica pela possibilidade da análise do espaço geográfico municipal de maneira sistêmica e holística, possibilitando um conhecimento acurado da realidade municipal tanto por parte do poder público quanto da sociedade, tendo em vista que as ações e os problemas existentes possuem uma localização geográfica precisa.

Um conceito que se faz necessário para o presente trabalho é o de zoneamento, haja vista a importância do mesmo em um estudo de ordenamento territorial. O zoneamento deve ser visto como um instrumento cuja finalidade é auxiliar a formulação de políticas e estratégias de desenvolvimento a serem praticadas em um determinado território. Alguns pontos julgados relevantes devem ser almejados na elaboração do mesmo, conforme Becker e Egler (1996):

a) Representar instrumento técnico de informações sobre o território, necessária para a sua ocupação racional e uso sustentável dos recursos naturais;

b) Prover uma informação integrada de dados ambientais, sociais e econômicos, classificando o território de acordo com a sua capacidade de suporte ao uso e ocupação;

c) Ser condicionante de planejamento e de gestão para o desenvolvimento em bases sustentáveis, colocando-se como instrumento corretivo e estimulador desse desenvolvimento.

Nesse contexto, concorda-se com as idéias de Milaré (2000), que compatibilizar meio ambiente e desenvolvimento significa considerar os problemas ambientais dentro de um processo contínuo de planejamento, atendendo-se adequadamente às exigências de ambos e observando-se as suas inter-relações particulares em cada contexto sociocultural, político, econômico, ecológico e dentro de uma dimensão tempo/espaço.

Assim, o uso de um SIG possibilita a integração de dados ambientais e socioeconômicos em um ambiente digital, consentindo a consulta e análise dos dados georreferenciados visando o planejamento e a implementação de ações voltadas para o desenvolvimento sustentável do município.

Nesse viés de análise, inicialmente, apresenta-se na Figura 6 parte de uma ortofoto com a sobreposição dos temas presentes no SIG, percebendo-se na imagem uma perfeita identificação dos detalhes existentes no terreno, devido a sua resolução espacial de $20 \mathrm{~cm}$.

Conforme pontua Floriano (2004), o planejamento ambiental se associa ao planejamento estratégico da gestão municipal, tendo em vista que se deve partir da dimensão organizacional para avaliar a forma como o governo encara o meio ambiente, atuando de forma proativa e definindo os seus propósitos, objetivos e políticas a serem adotadas. Nesse contexto, 0 autor cita que os produtos de sensoriamento remoto são instrumentos importantes em estudos de zoneamento e gestão territorial.

Geografia Ensino \& Pesquisa, v. 16, n.2

p. 162 - 182, maio/ago. 2012

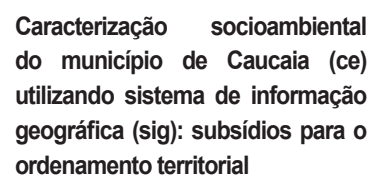




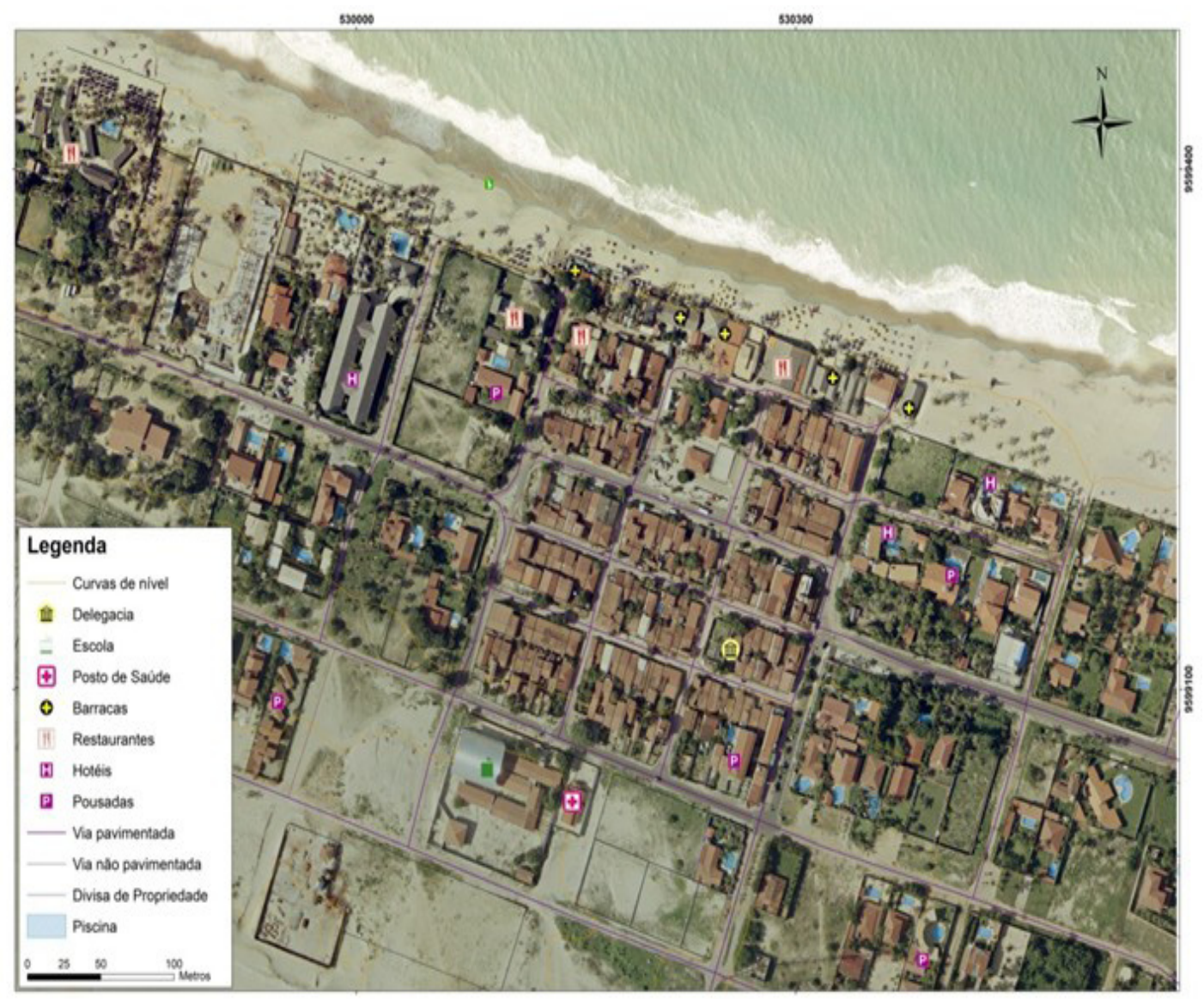

Figura 6- Parte de ortofoto contendo a sobreposição de temas vetoriais (vias de acesso, lotes, curvas de nível, equipamentos) presentes no SIG.

Fonte: Elaboração própria.

O objetivo da análise de dados socioeconômicos consiste em entender à dinâmica da ocupação territorial e o uso dos recursos naturais, considerando a forma como a ação dos agentes sociais se manifesta no território. Essa análise reconstrói as tendências históricas das formas de aparecimento das relações sociais e de produção no território, perpassadas pelos estudos demográficos, econômicos, sociais e de condições de vida (MMA, 2006).

Nesse contexto, exibe-se nas Figuras 7 e 8 respectivamente, a distribuição dos setores censitários de Caucaia contendo dados socioeconômicos oriundos do Censo Demográfico 2010 (IBGE, 2010) e uma consulta de quais setores possuem proporção de população com mais de 64 anos acima de 10\%, sendo esta última análise importante para o estabelecimento de ações públicas específicas voltadas para o contingente populacional idoso do município. 


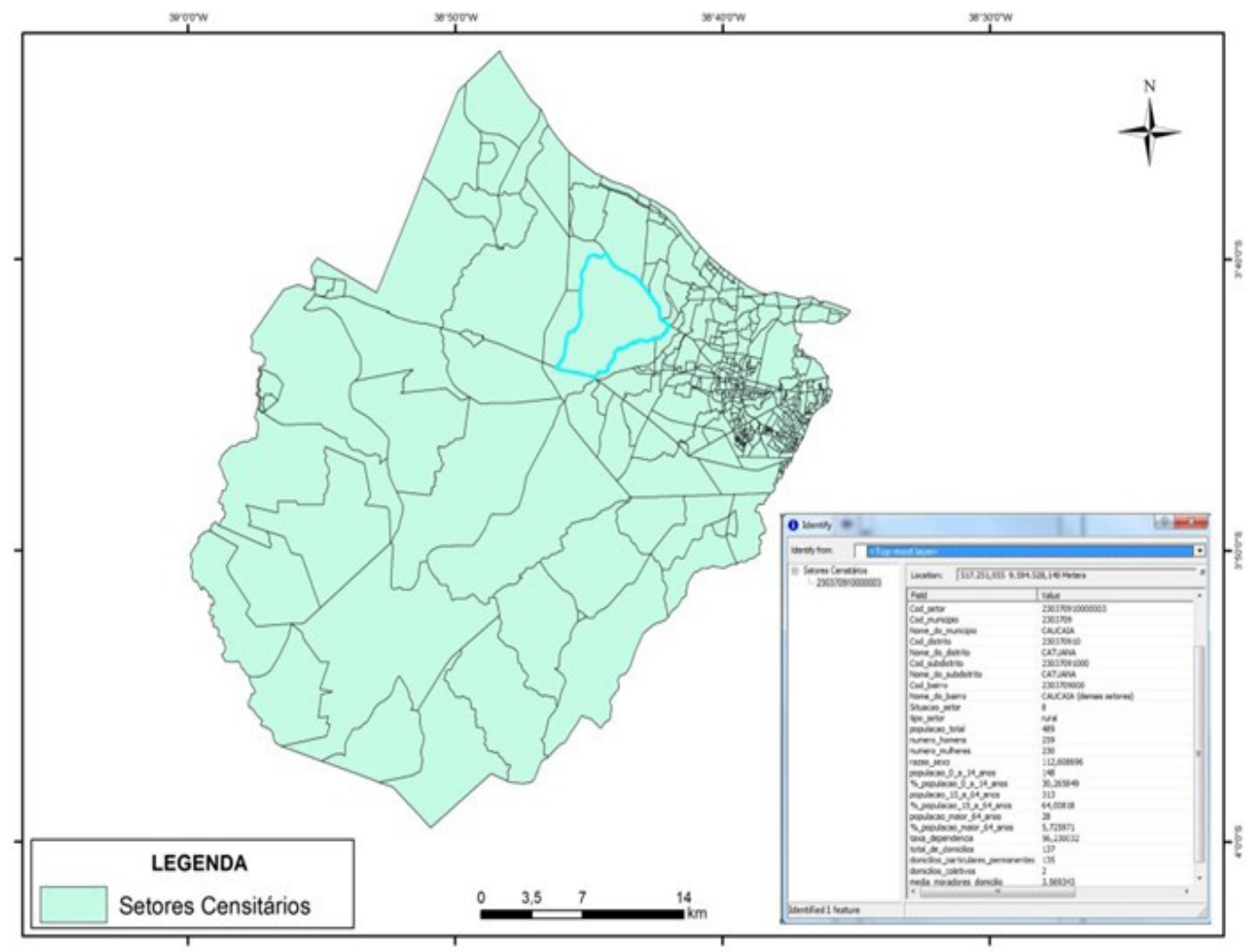

Figura 7- Atributos vinculados aos setores censitários de Caucaia. Fonte: Elaboração própria.

Geografia Ensino \& Pesquisa, v. 16, n.2 p. 162 - 182, maio/ago. 2012

Caracterização socioambiental do município de Caucaia (ce) utilizando sistema de informação geográfica (sig): subsídios para o ordenamento territorial

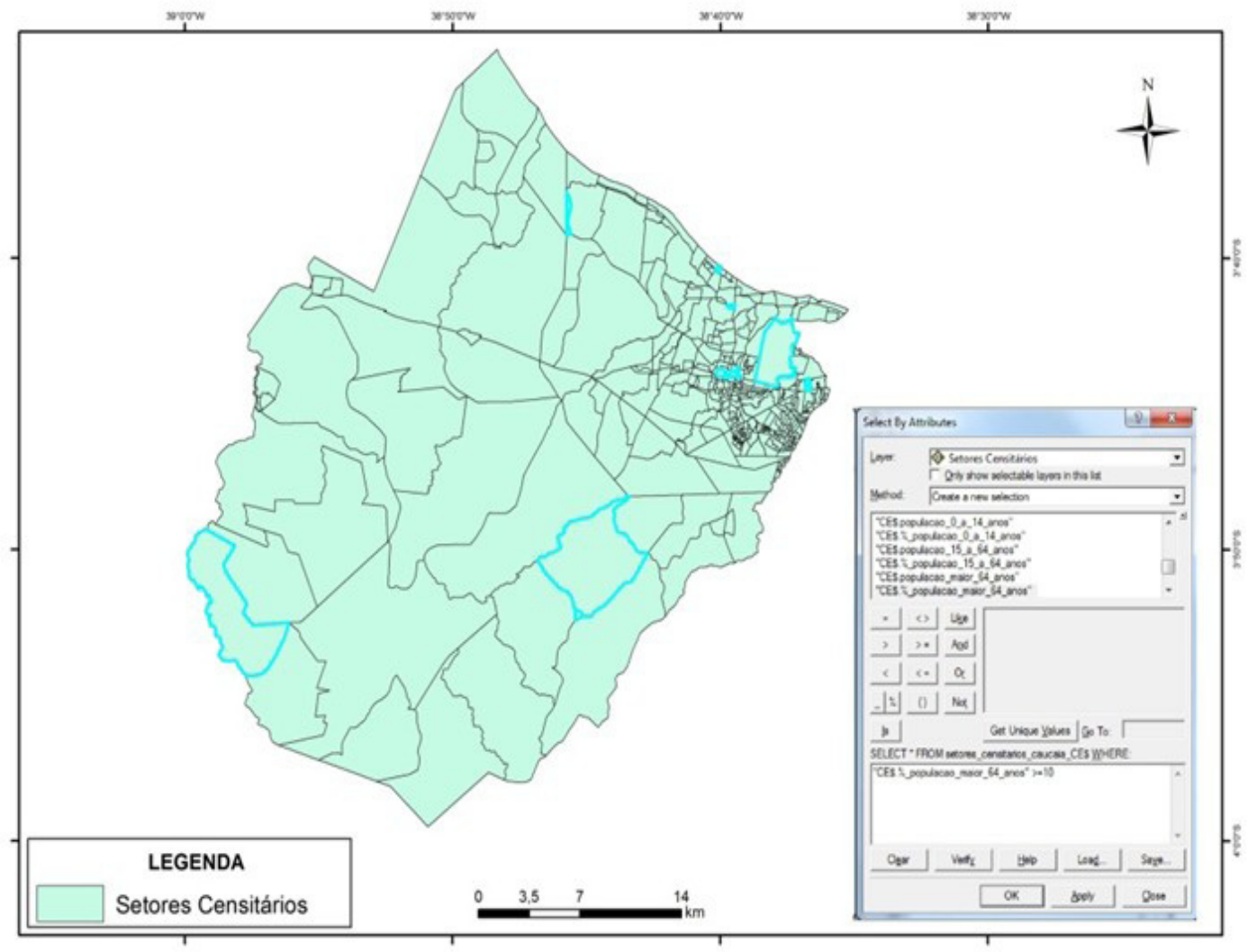

Figura 8- Seleção dos setores censitários (em azul) com percentual da população acima de 64 anos maior ou igual a $10 \%$.

Fonte: Elaboração própria. 
Dessa forma, o mapeamento de dados socioeconômicos permite uma regionalização capaz de delimitar subespaços para os quais possam ser definidas políticas públicas mais adequadas às suas especificidades. Assim, a espacialização de indicadores relacionados à demografia, renda, educação e saúde, constitui uma ferramenta fundamental em estudos de ordenamento do território.

Na Figura 9 exibe-se, como exemplo, a localização das escolas na sede urbana de Caucaia, onde se pode avaliar a distribuição espacial desse equipamento permitindo detectar problemas quanto à localização e antecipar as necessidades da sociedade em busca da equilibrada distribuição deste serviço urbano, reduzindo desigualdades espaciais e promovendo o desenvolvimento educacional em todas as áreas do município. Esta mesma análise pode ser realizada para outros equipamentos públicos, tais como os hospitais, postos de saúde e delegacias.

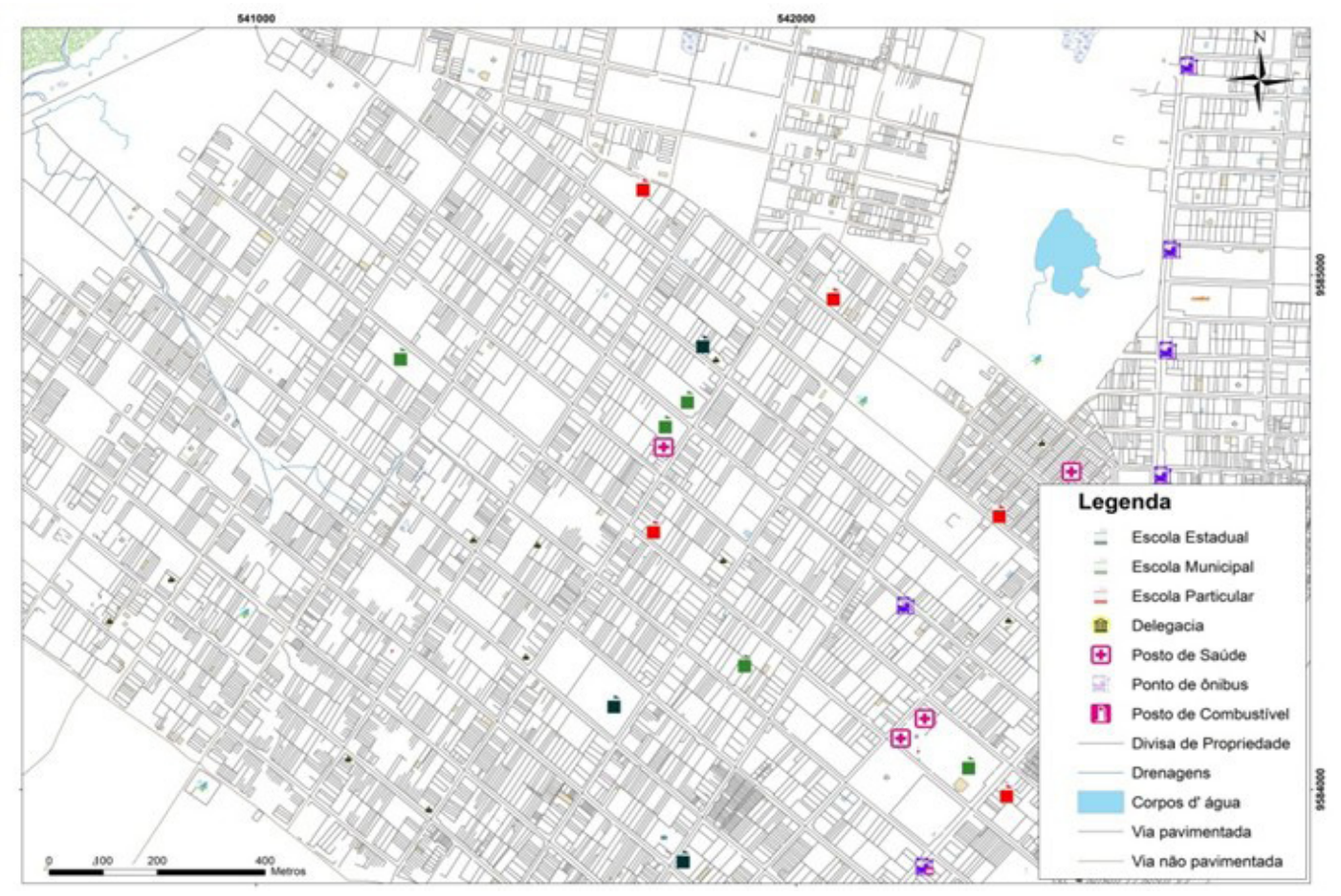

Figura 9- Exemplo da distribuição das escolas estaduais, municipais e particulares de Caucaia. Fonte: Elaboração própria.

Aliado à localização geográfica, tem-se vinculado aos temas mapeados atributos que caracterizam os mesmos. Mostra-se na Figura 10 uma consulta sobre o tema Creches, onde se utilizando o comando identificar do SIG sobre determinada creche, retorna-se uma série de dados, tais como o nome, endereço, bairro, CEP, telefone, entre outros. 


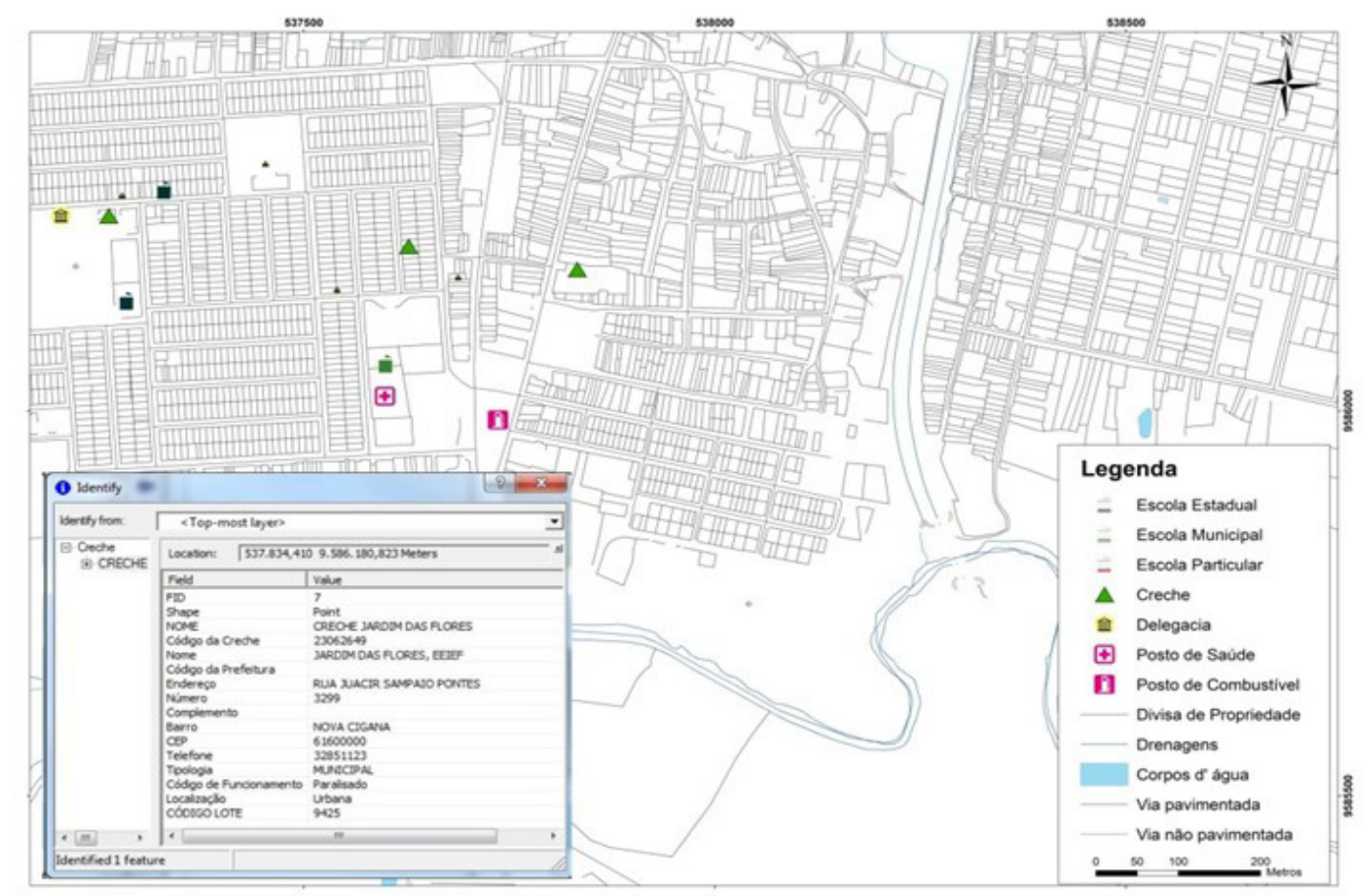

Figura 10- Exemplo de consulta aos atributos do tema creches.

Fonte: Elaboração própria.

Como citado anteriormente, no grupo Turismo foram mapeados os hotéis, pousadas, restaurantes, quiosques, barracas e os atrativos naturais. Utilizando as ferramentas de consulta do SIG podem-se localizar quais os restaurantes que estão a uma certa distância de um determinado hotel e qual o tipo de serviço que os mesmos prestam. Como exemplo selecionou-se o hotel Blue Wind e localizaram-se os restaurantes a menos de 300 metros do referido hotel, conforme apresentado na Figura 11.

Geografia Ensino \& Pesquisa, v. 16, n.2 p. 162 - 182, maio/ago. 2012

Caracterização socioambiental do município de Caucaia (ce) utilizando sistema de informação geográfica (sig): subsídios para o ordenamento territorial

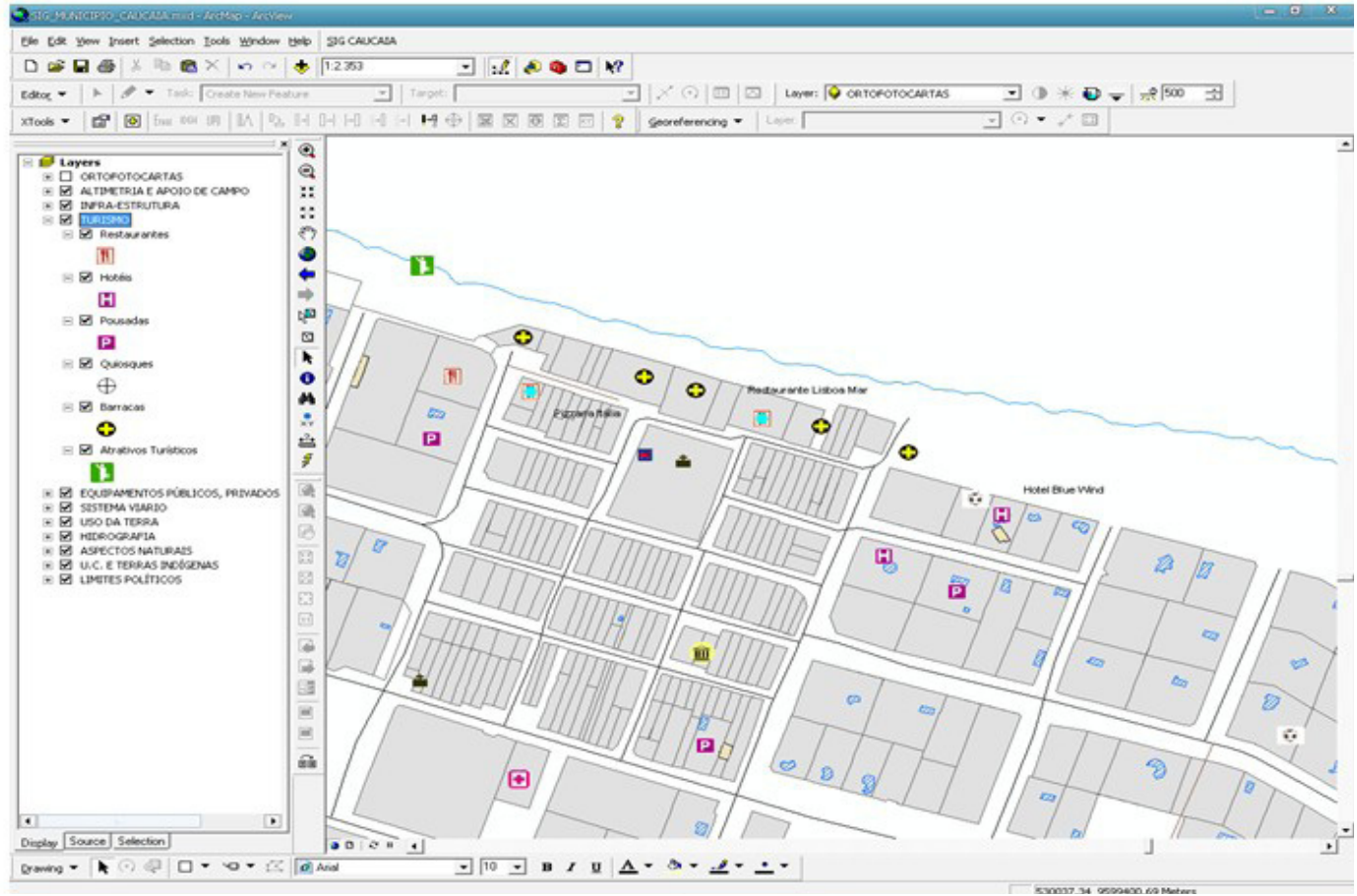

Figura 11- Imagem de consulta da seleção dos restaurantes (em azul) que estão a menos de 300 metros do hotel Blue Wind.

Fonte: Elaboração própria. 
Ainda em relação aos hotéis e pousadas, foram vinculados aos temas mapeados atributos que caracterizam os mesmos, tais como o nome, razão social, faixa de valores, número de acomodações, sendo possível a realização de consultas sobre estes temas, como por exemplo, a localização de pousadas que possuem valor de diária inferior a $R \$ 50,00$. Outro tipo de informação presente no SIG são os hiperlinks que foram associados ao mapeamento cartográfico fornecendo mais informações sobre os temas, conforme exibido na Figura 12.

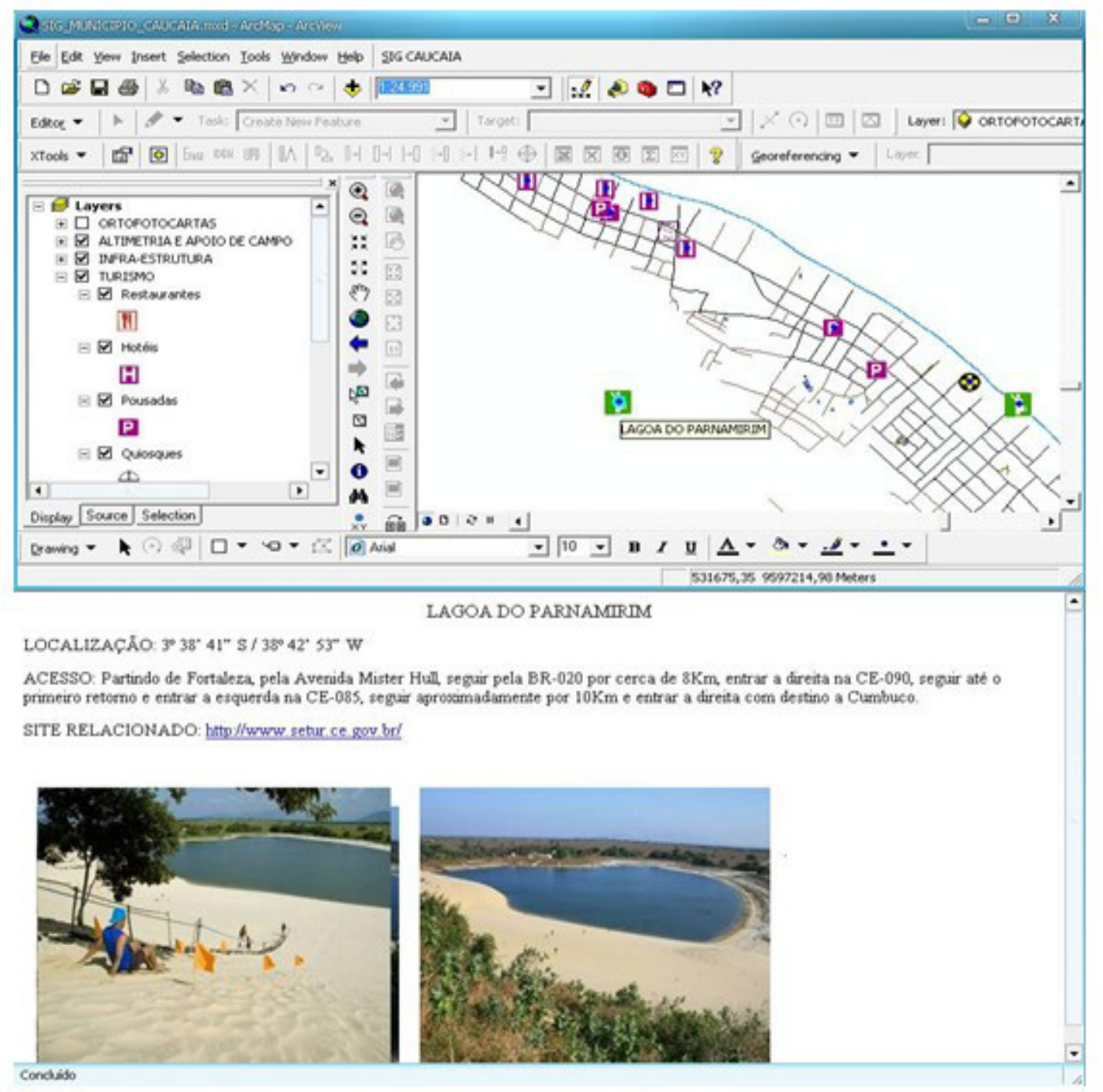

Figura 12- Imagem de consulta de hiperlink para o tema de Atrativos naturais - Lagoa do Parnamirim. Fonte: Elaboração própria.

No tocante ao grupo de uso da terra, como comentado anteriormente, foi relacionado ao tema Lotes informações cadastrais do banco de dados da Secretaria de Finanças, permitindo-se realizar consultas por atributos (Figura 13) e por localização. Pode-se elaborar, por exemplo, mapas temáticos com a distribuição dos lotes por tipo de atividade (residencial, comercial e industrial), bem como avaliar se o imóvel é isento ou não quanto ao pagamento de IPTU.

Neste aspecto, o SIG elaborado torna-se uma ferramenta fundamental para ampliar os recursos arrecadados no município com a cobrança do IPTU, uma vez que a geração de um cadastro georreferenciado permite que seja agilizada, e de forma mais confiável, a implementação do imposto.
Geografia Ensino \& Pesquisa, v. 16, n.2 p. 162 - 182, maio/ago. 2012

Medeiros, C. N.; Souza, M. J. N; Gomes, D. D. M.; Albuquerque, E. L. S. 


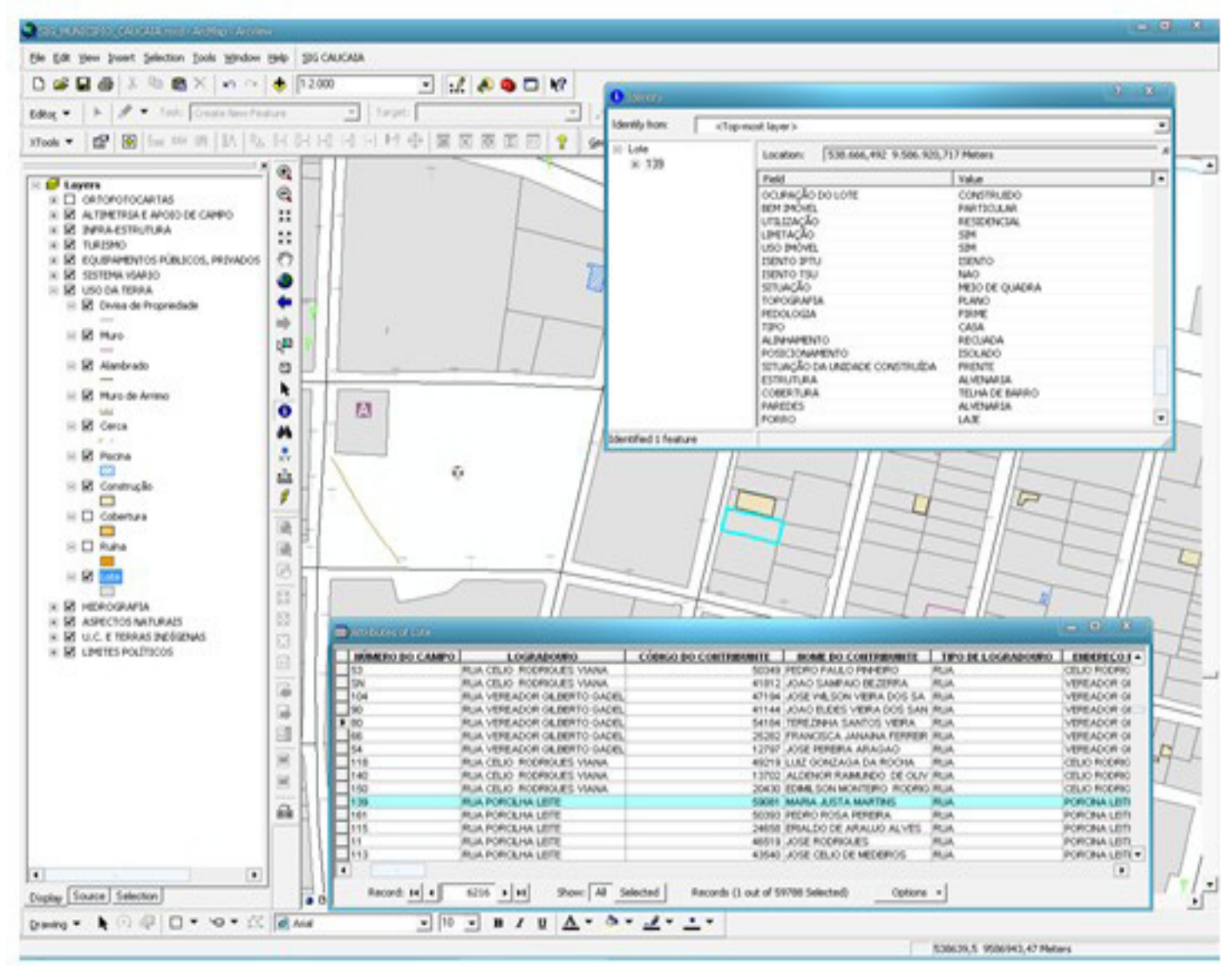

Figura 13- Imagem de consulta dos atributos vinculados aos temas de lotes visando à elaboração de um cadastro georreferenciado.

Fonte: Elaboração própria.

Dessa forma, o SIG de Caucaia permite a visualização, consulta e análise dos temas mapeados, otimizando o acesso à informação no intuito da tomada correta de decisão, visando 0 ordenamento territorial do município.

\section{Considerações finais}

As distintas análises exemplificadas sobre o SIG de Caucaia mostraram que a capacidade de integração de dados de diversas naturezas aumentam a percepção da observação e da análise, auxiliando de forma significativa à gestão pública, gerando com isso dados para a compreensão da realidade geográfica, e fornecendo informações para a tomada correta da decisão, aplicação e arrecadação de recursos financeiros, planejamento de projetos sociais, entre outras finalidades.

Destarte, o planejamento urbano deve ser norteado através de um conjunto de decisões

Geografia Ensino \& Pesquisa, v. 16, n.2 p. 162 - 182, maio/ago. 2012

Caracterização socioambiental do município de Caucaia (ce) utilizando sistema de informação geográfica (sig): subsídios para o ordenamento territorial baseadas em características socioambientais, nas necessidades da sociedade e nos fatores operacionais de cada região, e as ações municipais precisam ser voltadas para a melhoria de qualidade de vida da população, compatíveis com a realidade dos municípios. Para tanto, se torna necessário conhecer as cidades segundo as suas potencialidades físicas, sociais e econômicas, principalmente em virtude dos diferentes cenários existentes.

Muitas outras informações estão contidas e disponíveis no SIG, além das citadas neste trabalho. Outras poderão ser acrescentadas futuramente, pois o sistema oferece praticidade, podendo ser atualizado e ajustado a todo o momento, segundo a necessidade da demanda. Atualmente, o SIG encontra-se implantado na Prefeitura Municipal de Caucaia, podendo ser utilizado 
pelos gestores municipais para planejar a ocupação mais racional do espaço geográfico do município, em virtude da rapidez com que os resultados são obtidos e pela visão sinóptica da realidade representada espacialmente, devido ao alto grau de confiabilidade dos dados e pelas informações geradas.

Ressalta-se que foi realizado treinamento com técnicos da prefeitura, IPECE e SETUR visando à qualificação dos mesmos no manuseio do sistema, capacitando-os a fim de que possam realizar análises, consultas, bem como atualizar o sistema com novos dados.

Vale salientar que em virtude da eficiência dos SIG's nas questões relacionadas ao ordenamento territorial municipal, inserem-se nesse contexto, e em consonância com o Estatuto da Cidade, as novas perspectivas direcionadas para a Política Nacional de Desenvolvimento Urbano, com foco no Plano Diretor e nas políticas de planejamento e gestão urbana, temática essa de suma importância e a ser implementada no município em questão.

0 que se pretende, portanto, é fornecer informações atualizadas e espacializadas concernentes à caracterização socioambiental do município, esperando-se que este trabalho possa contribuir para o ordenamento territorial de Caucaia, uma vez que o município está passando por um desenvolvimento econômico acentuado, com atividades econômicas relacionadas aos setores de serviços e indústria, assim como um acelerado crescimento urbano.

\section{Referências}

ALBUQUERQUE, E. L. S. SISTEMA DE INFORMAÇÃO GEOGRÁFICA MUNICIPAL: novas perspectivas aplicadas à gestão territorial do município de Horizonte - Ceará. 2011. Monografia (Especialização em Geoprocessamento) - Universidade Estadual do Ceará (UECE), Fortaleza - CE.

BOLSTAD, P. 2002. GIS Fundamentals. White Bear Lake, Minn: Eider Press.

BRASIL. Ministério das Cidades. 2010. Capacitação. Disponível em: <http://www.cidades. gov.br/capacitacao-1/proext>. Acesso em: 29 jun. 2011a.

BECKER, B. K.; EGLER, C. A. G. Detalhamento da Metodologia para Execução do Zoneamento Ecológico- Econômico pelos Estados da Amazônia Legal. Brasília. SAE-Secretaria de Assuntos Estratégicos/ MMA - Ministério do Meio Ambiente. 1996.

BRASIL. Governo Federal - Ministério do Meio Ambiente, dos Recursos Hídricos e da Amazônia Legal. Diretrizes metodológicas para o zoneamento ecológico-econômico do Brasil. Brasília, 2006. CD-ROM.

BRASIL, Decreto 89.817 de 20 de junho de 1984. Estabelece as Instruções Reguladoras das Normas Técnicas da Cartografia nacional. Diário Oficial da República Federativa do Brasil, Brasília. 1984.

CLARKE, K. C. 2002. Getting Started with Geographic Information Systems. 4th ed. New York. Prentice Hall.

CUNHA, J.A.2001. Agestão municipal através de tecnologia de geoprocessamento e cadastro urbano: Gerenciamento de dados físicos e sócio-econômicos do município de Serra Negra do Norte-RN. Dissertação de Mestrado - PPGeO, UFRN, 101p.

CONCAR - Comissão Nacional de Cartografia, 2010. Plano de Ação para Implantação da Infraestrutura Nacional de Dados Espaciais. Disponivel em: http://www.concar.ibge. gov.br. Acesso em: 22/06/2011.
Geografia Ensino \& Pesquisa, v. 16, n.2 p. 162 - 182, maio/ago. 2012

Medeiros, C. N.; Souza, M. J. N; Gomes, D. D. M.; Albuquerque, E. L. S. 
FLORIANO, E. P. Planejamento Ambiental, Caderno Didático nº 6, $1^{\mathrm{a}}$ ed. 2004. 54p.

IBGE - Instituto Brasileiro de Geografia e Estatística. 2002. Áreas Territoriais dos Estados e Municípios Brasileiros. Disponível na internet: www.ibge.gov.br/home/geografia/ areaterritorial/resolucao.shtm. Acessado dia 05/02/2012.

GIANUCA, K. S.; TAGLIANI, C. R. Análise em um Sistema de Informação Geográfica (SIG) das alterações na paisagem em ambientes adjacentes a plantios de pinus no distrito de Estreito, município de São José do Norte, Brasil. Revista de Gestão Costeira Integrada. V. 12 (1). p. 43-55. 2012.

IBGE - Instituto Brasileiro de Geografia e Estatística. 2010. Censo Demográfico de 2010. Disponível na internet: www.sidra.ibge.gov.br. Acessado dia 12/09/2011.

IPECE - Instituto de Pesquisa e Estratégia Econômica do Ceará. 2008. Base Cartográfica do Pólo Ceará Costa do Sol. Nota técnica $n^{0} 35$. Disponível na internet: www.ipece.ce.gov.br. Acesso dia 09/01/2012.

IPECE - Instituto de Pesquisa e Estratégia Econômica do Ceará. 2010. Perfil Básico Municipal de Caucaia. Disponível na internet: www.ipece.ce.gov.br. Acessado dia 12/11/2011.

MEDEIROS, C. N. Geoprocessamento na Gestão Municipal: Mapeamento do Meio Físico e Socioeconômico do Município de Parnamirim - RN. 2004. Dissertação de Mestrado PPGeO, UFRN, $140 \mathrm{p}$.

MEDEIROS, C.N.; PETTA, R.A.; DUARTE, C.R. Mapeamento de indicadores socioeconômicos do município de Parnamirim (RN) utilizando técnicas de geoprocessamento. Revista Geografia, v. $30, n^{\circ} 3$, p. 507-524. 2005.

MILARÉ, E. Direito do Ambiente. São Paulo: Revista dos Tribunais. 2000.

MITCHELL, A. 2005. The ESRI Guide to GIS Analysis, Vol. 2. Spatial Measurements and Statistics. Redlands. ESRI Press.

MORAIS, L. F. S. Para onde sopram os ventos do Cumbuco. Impactos do turismo no litoral de Caucaia, Ceará. 2010. Dissertação de Mestrado do Programa de Pesquisa e Pós-Graduação em Geografia - Universidade Estadual do Ceará, Fortaleza - CE, 128 p.

SANTOS, R. F. Planejamento Ambiental Teoria e Prática. São Paulo: Ed. Oficina de Textos, 2004.

SCARLATO, F.C. e PONTIN, J.A. O Ambiente Urbano. Editora Atual S.A., São Paulo-SP, 79p. 1999.

SILVA, A. B. Sistemas de Informações Geo-referenciadas: Conceitos e fundamentos. Campinas: Editora da Unicamp, 1999.

Geografia Ensino \& Pesquisa, v. 16, n.2 p. 162 - 182, maio/ago. 2012

Caracterização socioambiental do município de Caucaia (ce) utilizando sistema de informação geográfica (sig): subsídios para o ordenamento territorial
SOUZA, M.J.N. Contribuição ao estudo das unidades morfoestruturais do Estado do Ceará. Revista de Geologia, v. 1, DEGEO/UFC, p. 73-91. 1988

SOUZA, M.J.N.; BRANDÃO, R. L.; CAVALCANTE, I. N. Impactos ambientais em zonas costeiras: Principais problemas relacionados ao meio físico da Região Metropolitana de Fortaleza. I Simpósio Sobre Processos Sedimentares Ambientais na Zona Costeira do Nordeste do Brasil. Anais. Recife-PE. 1995. 


\section{Correspondência:}

Cleyber Nascimento de Medeiros- Instituto de Pesquisa e Estratégia Econômica do Ceará - IPECE. Av. General Afonso Albuquerque Lima, S/N, Bairro Cambeba, Centro Administrativo do Estado, CEP 60.822-325, Fortaleza, Ceará.

E-mail: cleyber.medeiros@ipece.ce.gov.br

Recebido em 30 de janeiro de 2012.

Revisado pelo autor em 10 de julho de 2012.

Aceito para publicação em 30 de julho de 2012.

Geografia Ensino \& Pesquisa, v. 16, n.2 p. 162 - 182, maio/ago. 2012

Medeiros, C. N.; Souza, M. J. N; Gomes, D. D. M.; Albuquerque, E. L. S. 